\title{
Zawał serca u 34-letniej pacjentki. Czy terapia przeciwtrądzikowa niesie ze sobą zwiększone ryzyko zakrzepicy i nagłego zatrzymania krążenia?
}

\author{
Myocardial infarction in a 34-year-old patient. \\ May acne medications promote thrombosis and cardiac arrest?
}

\author{
Łukasz Figiel, Mateusz Jaśkowski, Przemysław Trzciński, Piotr Lipiec, Jarosław D. Kasprzak \\ Klinika Kardiologii Katedry Kardiologii Uniwersytetu Medycznego w Łodzi, Szpital im. Wł. Biegańskiego
}

\section{Streszczenie}

Zawał serca to jedna z najważniejszych jednostek chorobowych dzisiejszej medycyny. W Polsce na zawał serca zapada rocznie około 100 tys. osób, a z powodu jego powikłań notuje się co roku kilkanaście tysięcy zgonów. Mimo to ciągle zdarzają się przypadki (dotyczy to szczególnie młodych osób), w których napotyka się trudności z ustaleniem przyczyny niedokrwienia mięśnia sercowego. W niniejszym artykule zaprezentowano przypadek zawału serca powikłanego nagłym zatrzymaniem krążenia (SCA) u 34-letniej pacjentki, przewlekle leczącej się z powodu nawracających zmian trądzikowych. Należy nadmienić, że SCA to jedno z najcięższych powikłań zawału serca - śmiertelność jest niezwykle wysoka, a skuteczność niesionej choremu pomocy w głównej mierze zależy od szybkości i doświadczenia osób lub zespołów ratowniczych prowadzących czynności reanimacyjne. Dlatego też bardzo istotne jest ustalenie, czy prowadzona przez pacjentkę terapia przeciwtrądzikowa i przyjmowane przez nią leki mogły się przyczynić do rozwoju tego poważnego stanu.

Słowa kluczowe: zawał serca, nagłe zatrzymanie krążenia, zakrzepica

Folia Cardiologica 2016; 11, 5: 451-454

\section{Wstęp}

Zawał serca powikłany nagłym zatrzymaniem krążenia (SCA, sudden cardiac arrest) to stan wiążący się z wysokim ryzykiem zgonu [1]. Kluczowymi czynnikami przeżycia wydają się szybko podjęta resuscytacja krążeniowo-oddechowa oraz natychmiastowy transport do ośrodka specjalistycznego. Opisano wiele czynników wywołujących ten nagły stan, lecz ciągle zdarzają się pacjenci, u których przyczyny zawału serca, zwłaszcza u młodych osób, nie są jednoznaczne. Poniżej przedstawiamy jeden z takich przypadków.

\section{Opis przypadku}

Pacjentka w wieku 34 lat, nielecząca się do dotychczas z przyczyn kardiologicznych, niepaląca, bez zaburzeń gospodarki lipidowej, została przyjęta do Kliniki Kardiologii 6 października 2012 roku w bardzo ciężkim stanie z powodu nagłego pozaszpitalnego zatrzymania krążenia (przywieziona przez pogotowie ratunkowe po skutecznej defibrylacji [migotanie komór] i prowadzonej wcześniej przez męża resuscytacji krążeniowo-oddechowej).

W badaniu przedmiotowym przy przyjęciu ustalono wzrost równy $162 \mathrm{~cm}$, masę ciała 62 kg, wskaźnik masy 


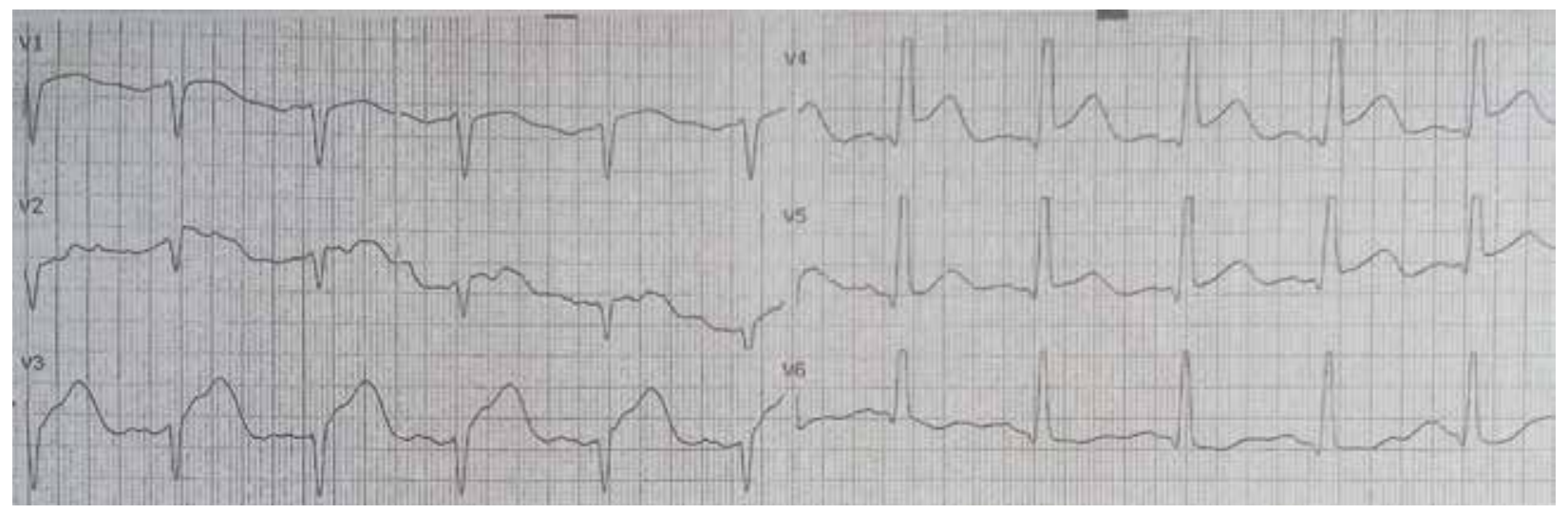

Rycina 1. Zapis EKG pacjentki podczas przyjęcia - fala Pardeego w odprowadzeniach V1-V4

ciała (BMI, body mass index) 23,6 kg/m², ciśnienie tętnicze wynosiło 130/80 mm Hg. Pacjentkę przypisano do IV klasy według Cardiac Resuscitation (CCS), I klasy według Killipa. W badaniu elektrokardiograficznym (EKG) wykazano uniesienia odcinka ST o typie fali Pardeego w odprowadzeniach V1-V4 (ryc. 1). W badaniach laboratoryjnych stwierdzono znamiennie podwyższone wartości markerów martwicy mio-

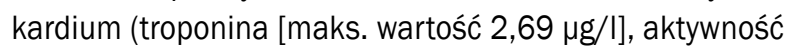
frakcji mięśniowej kinazy kreatynowej [CK-MB, creatine kinase myocardial bound] [maks. wartość 59,4 $\mu \mathrm{g} / \mathrm{I}]$ ). W badaniu echokardiograficznym obserwowano odcinkowe zaburzenia kurczliwości pod postacią hipokinezy koniuszka, 2/3 dystalnych przegrody, 1/3 dystalnej ściany bocznej oraz dystalnej ściany przedniej mięśnia lewej komory z frakcją wyrzutową (EF, ejection fraction) równą 50\%.

Pacjentkę w stanie ciężkim, z rozpoznanym zawałem ściany przedniej przetransportowano do pracowni hemodynamiki, gdzie w trybie pilnym wykonano koronografie, podczas której stwierdzono amputację gałęzi przedniej zstępującej, tuż za jej odejściem od lewej tętnicy wieńcowej (ryc. 2), bez zmian w pozostałych naczyniach. Wykonano jednoczasowo trombektomię aspiracyjną (ewakuując dużą skrzeplinę) oraz zabieg pierwotnej koronoplastyki dozawałowej gałęzi przedniej zstępującej (LAD, left anterior descending) z implantacją 2 stentów uwalniających amfillimus CRE $3 \times 25 \mathrm{~mm}, 3,0 \times 16 \mathrm{~mm}$ i podaniem abcyksymabu, uzyskując pełne otwarcie naczynia i napływ obwodowy TIMI 3. Przebieg zabiegu oraz wczesny okres dalszej hospitalizacji nie przyniosły żadnych powikłań. Obserwowano enzymatyczną i elektrokardiograficzną ewolucję zawału (ryc. 3). Pacjentkę w stanie ogólnym dobrym, z wdrożonym typowym leczeniem farmakologicznym zawału serca, 12 października 2012 roku przeniesiono na oddział rehabilitacji kardiologicznej w celu dalszego leczenia. W rocznej obserwacji nie wystąpiły powikłania - pacjentka czuje się dobrze, bez jakichkolwiek dolegliwości kardiologicznych oraz neurologicznych, w kontrolnym badaniu echokardiograficznym EF jest równa 58\%.

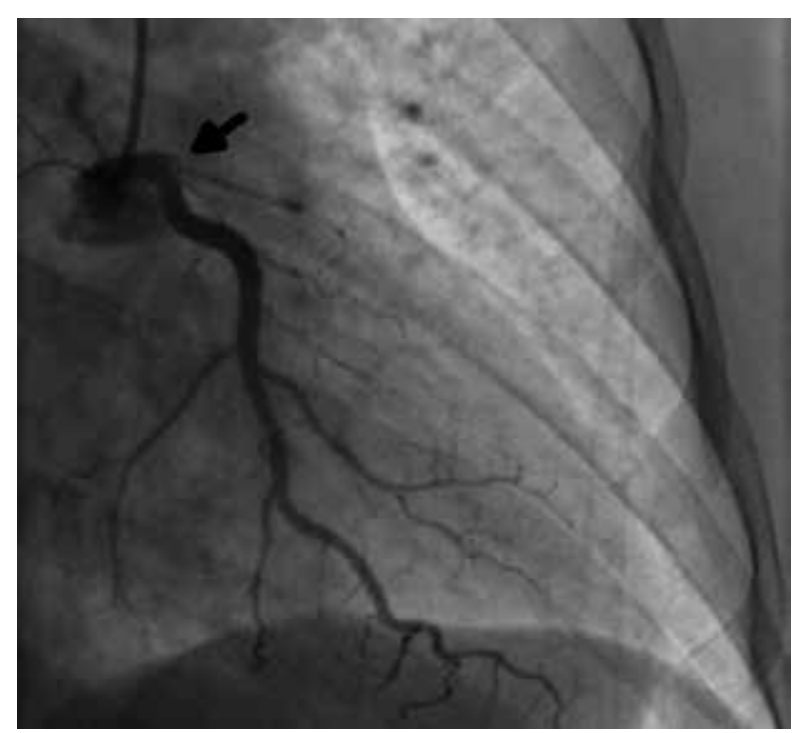

Rycina 2. Lewa tętnica wieńcowa w projekcji RAO 25 - amputacja gałęzi przedniej zstępującej

Poszukując czynników, które mogłyby wywołać stan bezpośredniego zagrożenia życia, ustalono, że chora nie paliła tytoniu oraz nie spożywała alkoholu. W badaniach biochemicznych stężenie cholesterolu całkowitego było w normie, cholesterol frakcji LDL wynosił $61 \mathrm{mg} / \mathrm{dl}$. Od 18. roku życia pacjentka leczyła się z powodu nasilonego trądziku - terapię rozpoczęła, przyjmując najpierw przez 5 miesięcy Roaccutane ${ }^{\circledR}$ (isotretinoinum) oraz pomocniczo preparat Diane $35^{\circledR}$ (cyproteroni acetas, ethinylestradiolum). Po ustąpieniu zmian trądzikowych zaczęła przyjmować preparat antykoncepcyjny Yasmin ${ }^{\circledR}$ (ethinylestradiolum, drospirenonum), jednak z powodu narastania objawów trądziku powróciła około 2 lat przed zawałem do leku Diane $35^{\circledR}$, przyjmując go przez 10 miesięcy. Dodatkowo w 2010 roku zastosowano u niej powtórnie roczną kurację preparatem Isotec ${ }^{\circledR}$ (isotretinoinum). W styczniu 2011 roku pacjentka zaszła w ciążę, w czasie której przerwała terapię, 


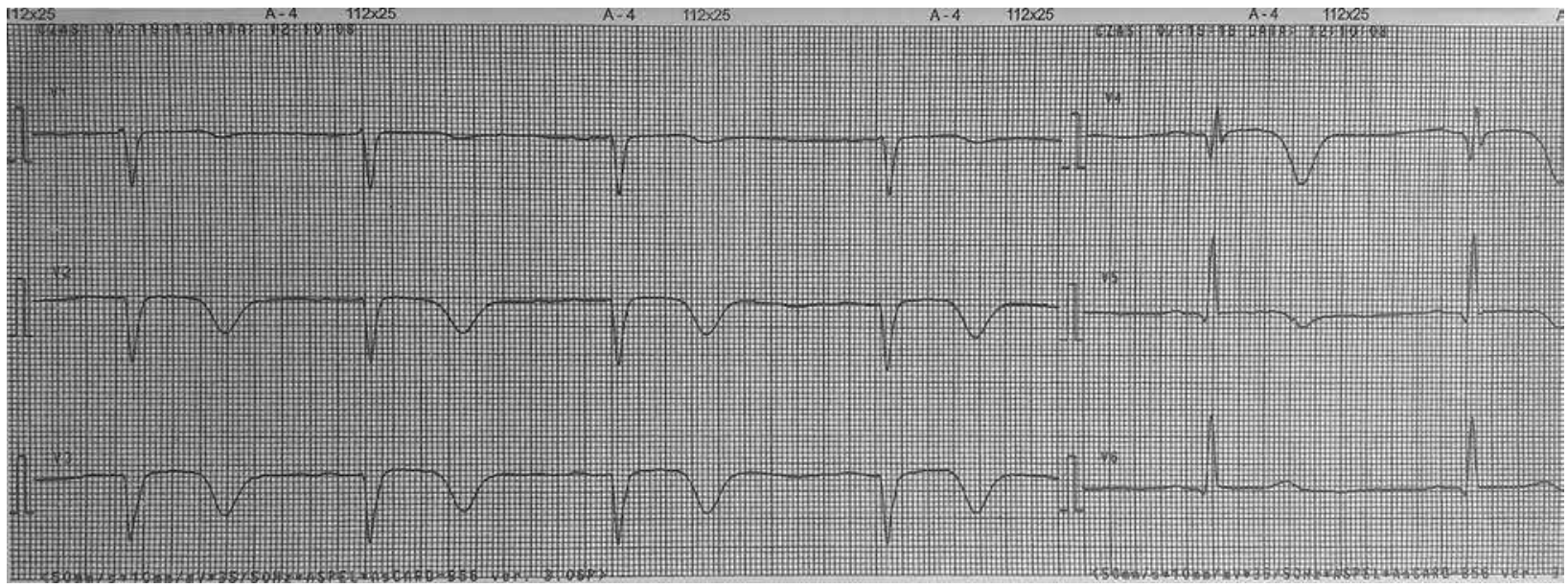

Rycina 3. Zapis EKG pacjentki - elektrokardiograficzna ewolucja zawału serca

po czym po porodzie w roku 2012 i wykonaniu badania ginekologicznego oraz dodatkowych badań biochemicznych ze względu na nasilenie zmian trądzikowych powróciła do przyjmowania Diane $35^{\circledR}$.

\section{Omówienie}

Nagłe zatrzymanie krążenia to ciągle bardzo poważny problem we współczesnej medycynie, śmiertelność jest ogromna, a skuteczność niesionej choremu pomocy zależy w głównej mierze od szybkości i doświadczenia osób lub zespołów ratowniczych prowadzących czynności reanimacyjne [2]. Przyczyną SCA u opisywanej przez nas pacjentki był zawał serca spowodowany zakrzepicą LAD lewej tętnicy wieńcowej. Rozpoznanie to może dziwić, biorąc pod uwagę wiek pacjentki oraz nikłe czynniki ryzyka zakrzepicy oraz choroby niedokrwiennej serca, należy jednak zwrócić szczególną uwagę na farmakoterapię, jaką chora otrzymywała w przebiegu leczenia trądziku.

Pierwszym lekiem, który przyjmowała pacjentka jest retinoid Roaccutane ${ }^{\circledR}$ (następnie zamiennik Isotec ${ }^{\circledR}$ ) zawierający substancję czynną isotretinoinum, preparat wskazany w leczeniu chorób łojotokowych skóry, między innymi trądziku [3]. Preparat ten ma reguluje syntezę zewnętrznej warstwy skóry oraz wydzielanie łoju. Choć terapia jest bardzo skuteczna i zrewolucjonizowała leczenie trądziku, wiąże się z pewnymi ograniczeniami i poważnymi możliwymi działaniami niepożądanymi - od najczęstszych, takich jak wysychanie błon śluzowych czy mdłości, do mniej częstych takich jak zaburzenia procesów krzepnięcia krwi mogących prowadzić do zakrzepicy, która pojawiła się u naszej pacjentki. Warto zaznaczyć, że w jednym z badań przekrojowych, w którym poddano analizie ponad 870 pacjentów przyjmujących izotretynoiny pod kątem występowania powikłań sercowo-naczyniowych typu: udar, zakrzepica żyına lub tętnicza, zawał serca, stwierdzono, że iloraz szans (OR, odds ratio) wystąpienia zawału serca przy jednoczesnym przyjmowaniu leków przeciwtrądzikowych jest równy 2,00 (OR 2,00; 95-proc. przedział ufności [Cl, confidence interval] 0,50-8,00), nie wykazano jednak istotności statystycznej tych wyników [4].

Kolejnym lekiem jest Diane $35^{\circledR}$ (cyproteroni acetas, ethinylestradiolum). Wskazaniem do jego stosowania jest między innymi trądzik u kobiet szczególnie z łojotokiem. Hormonalna terapia przeciwtrądzikowa to udokumentowana i skuteczna metoda leczenia [5], jednak kontrowersje związane z preparatem Diane $35^{\circledR}$ są powszechnie znane. Został on wycofany z obiegu we Francji po śmierci czterech Francuzek z powodu powikłań zatorowo-zakrzepowych będących jednym z działań niepożądanych stosowania tego leku [6].

Analizując przyjmowane długotrwale przez pacjentke w ramach terapii przeciwtrądzikowej leki, tj. izotretynoinę oraz octan cyproteronu z etynyloestradiolem, oraz ich działanie łącznie z działaniami niepożądanymi, można stwierdzić, że prawdopodobnie mogły one istotnie przyczynić się do powstania zakrzepicy LAD i co za tym idzie - wystąpienia zawału serca powikłanego nagłym zatrzymaniem krążenia. Nie bez znaczenia jest też pewnie terapia antykoncepcyjna $\left(\right.$ Yasmin $\left.^{\circledR}\right)$, która może wpływać na zaburzenia zakrzepowo-zatorowe [7].

\section{Podsumowanie}

Podsumowując, intensywna terapia przeciwtrądzikowa może sprzyjać powstawaniu powikłań zakrzepowych, dlatego powinna być stale monitorowana oraz wprowadzana tylko w razie istotnych wskazań.

\section{Konflikt interesów}

Autorzy nie zgłaszają konfliktu interesów. 


\section{Abstract}

Myocardial infarction is still one of the most important problems of modern medicine. Every year in Poland, about 100,000 people have a heart attack, and because of its complications several thousand dies. Despite this, there are still cases (especially among young people) where we encounter difficulty in determining the causes of myocardial ischemia. We present a case of myocardial infarction complicated by sudden cardiac arrest (SCA) in 34-year-old female patient, who was treated with anti-acne therapy. It should be noted that the SCA is one of the most serious complications of myocardial infarction, mortality is enormous, and patient survival depends largely on quick and professional resuscitation. That is why it is very important to determine whether patient anti-acne therapy may result in development of this serious condition. The analysis of this case is presented in this article.

Key words: myocardial infarction, sudden cardiac death, thrombosis

Folia Cardiologica 2016; 11, 5: 451-454

\section{Piśmiennictwo}

1. Sadeghi R., Adnani N., Sohrabi M.R. i wsp. Risk of sudden cardiac death. ARYA Atheroscler. 2013; 9: 274-279.

2. Rakić D., Rumboldt Z., Carević V. i wsp. In-hospital cardiac arrest and resuscitation outcomes: rationale for sudden cardiac death approach. Croat. Med. J. 2005; 46: 907-912.

3. Cunliffe W.J., van de Kerkhof P.C., Caputo R. i wsp. Roaccutane treatment guidelines: results of an international survey. Dermatology 1997; 194: 351-357.
4. Bérard A., Azoulay L., Nakhai-Pour H.R. i wsp. Isotretinoin and the risk of cardiovascular, cerebrovascular and thromboembolic disorders. Dermatology 2011; 223: 45-51.

5. Tan J. Hormonal treatment of acne: review of current best evidence. J. Cutan. Med. Surg. 2004; 4: 11-15.

6. Wooltorton E. Diane-35 (cyproterone acetate): safety concerns. CMAJ 2003; 168: 455-456.

7. Trenor C.C., Chung R.J., Michelson A.D. i wsp. Hormonal contraception and thrombotic risk: a multidisciplinary approach. Pediatrics 2011; 127: 347-357. 